\title{
Application of Mind Mapping in Emergency Nursing Teaching for Nursing Students in High Vocational Colleges
}

\author{
Bo Jing, Qingrong Qin, Dongming Sun \\ School of Nursing \\ Binzhou Polytechnic \\ Binzhou, Shandong, 256600, China
}

\begin{abstract}
This work discussed the application and effect evaluation of mind mapping in the emergency nursing teaching of the higher vocational nursing major. The experimental research was carried out on students in the 16th and 17th grades respectively, and 259 students from two classes of 16th grade and 249 students from two classes of 17th grade were divided into experimental group and control group respectively. Before the research, the internal Chi-square test was conducted according to five grades of students' comprehensive scores in the previous semester: excellent (average score 90-100), good (average score 80-89), medium (average score 70-79), pass (average score 60-69) and fail (average score less than or equal to 59). There was no statistical difference in the internal composition of students ( $\mathbf{p}>0.05, p>0.05)$, so it was comparable. The experimental group applied the mind mapping teaching program to teach emergency nursing courses, in contrast, the control group used the traditional teaching method. At the end of the semester, the final grades of the two groups of students were compared. The scores of the experimental group were significantly higher than those of the control group $(\mathbf{P}<0.001, P<0.001)$ for nursing students both in 16th grade and in 17th grade, indicating that the difference was statistically significant.
\end{abstract}

Keywords-Mind mapping; Higher vocational teaching; Emergency nursing; Clinical thought

\section{INTRODUCTION}

\section{A. Research background}

With the continuous advancement of curriculum reform and the rapid development of artificial intelligence and modern information technology, the classroom teaching mode at home and abroad continues to innovate and change in order to improve the quality of teaching. The new curriculum reform focuses on the quality of learning [1]. Among them, the educational intermediary system is a bridge between educators and educatees, which includes educational content and educational activities. However, the educational method determines how deep students can understand the knowledge they have learned and determines the development of students' intelligence and ability. The concept of mind mapping was proposed by Tony Buzan in 1971 as a visual thinking tool, which has been widely used in foreign educational practice [2]. Even students from well-known foreign universities are using mind mapping to learn, and believe that teaching based on mind mapping can significantly improve the effectiveness of teaching. Especially in recent years, countries are actively exploring new ways of teaching in the context of educational innovation, and constantly researching how to make students think better during the education process and how to improve students' academic achievement more effectively.

\section{B. Purpose and deficiency of this research}

1) Research purpose

Based on the teaching plan and teaching practice of mind mapping, this research concluded that mind mapping can improve students' academic achievement through data collection, collation and analysis. It brings reference of teaching practice to frontline teachers, which is conducive for teachers in conducting teaching based on mind mapping.

\section{2) Deficiency of this research}

First, the object of this research is only a part of the whole (sample), so it will still take a long time to verify if the educational model of mind mapping is universal. Therefore, its reliability and validity can only be proved by more extensive educational practice.

Second, the conclusion of the research only explains the influence of mind mapping teaching on the students' emergency nursing scores; however, it may also influence students' innovative thinking, integrated thinking and cognitive ability, which can be further studied.

Third, whether the mind-mapping has the same impact on students whose internal scores are not balanced required further empirical research.

\section{OVERVIEW OF Mind MAPPING APPLICATIONS}

Mind mapping is an organizational thinking tool emerged in the 1960s, which could express ideas and ways of understanding knowledge, problem-solving methods and innovative imagination in an orderly manner by drawing charts [3]. Generally, it takes the theme as the center and presents it in an organized, hierarchical and radiative way, which should fully display the organic integration of image thinking and logical thinking. Due to its good framework expression and graphic characteristics, now more and more are used in various fields. As a visual teaching aid, mind mapping in recent years has been applied into the field of nursing education [4]. The results show that mind mapping can improve students' interest 
in learning, enhance their memory and improve their clinical operation ability remarkably.

\section{Problems IN THE EMERgency NuRsing TEACHING}

Emergency nursing is a professional core competence course for the nursing major in higher vocational colleges. It is a clinical nursing course combining theory and practice and focuses on cultivating students' overall scientific thinking and clinical working methods. The clinical emergency technique commonly used in the course has detailed standards, which have higher requirements for students' overall clinical thinking ability. Since students majored in nursing only have two years to study theoretical knowledge in school, there is a contradiction between complex and difficult teaching contents and insufficient learning time. Therefore, how to improve students' self-learning ability, learning efficiency and overall thinking ability in limited teaching time becomes an important teaching and research content. The traditional teaching methods such as blackboard and PPT make knowledge points fragmented and inconsistency, which makes students produce fragmentary memories. If it cannot make a single skill operation coherent, then it will make students confused then they are facing dozens or even hundreds of points. However, a variety of lines, symbols, and colors used in the mind mapping can turn a large amount of information into a highly organized and colorful picture and input it into human brain, and finally convert it into long-term memory stored in students' memory. Mind mapping is widely used in various disciplines of the nursing major and has achieved remarkable results. Therefore, the mind mapping should be applied in emergency nursing teaching [5].

\section{OBJECT AND METHOD}

\section{A. Object}

Based on the principle of random sampling, 2 classes of class 15, 16 and 20 in 16th grade of higher vocational nursing major are randomly selected as the control group, and 2 classes of class 18, 19 and 17 are used as experimental group (There are 20 classes of higher vocational nursing major in 16th grade, every two classes from class 1 to class 16 are combined as a class according to the class number, classes 18 and 19 are taught in one classroom, and classes 17 and 20 are taught respectively). The Chi-square test of internal consistency between the control group and the experimental group shows no statistically significant difference, as shown in table I; 2 classes of class 1314 and 18 in 16th major are randomly selected as the control group, and 2 classes of class 1516 and 17 are used as the experimental group (class 13 and 14 are taught in one classroom). The analysis of internal consistency between the control group and the experimental group is shown in table II below.

TABLE I. COMPARISON OF INTERNAL CONSISTENCY BETWEEN THE CONTROL GROUP AND THE EXPERIMENTAL GROUP IN 16TH GRADE

\begin{tabular}{|c|c|c|c|c|c|c|c|c|}
\hline \multirow{3}{*}{ Group } & \multicolumn{6}{|c|}{ Average grade } & \multirow{3}{*}{$\begin{array}{c}\text { Person } \\
\text { Correlation value }\end{array}$} & \multirow{3}{*}{$\mathrm{P}$} \\
\hline & \multicolumn{2}{|c|}{ Excellent } & \multicolumn{2}{|c|}{ Good } & \multicolumn{2}{|c|}{ Medium } & & \\
\hline & $\begin{array}{c}\text { Number of } \\
\text { cases }\end{array}$ & Percentage (\%) & $\begin{array}{c}\text { Number of } \\
\text { cases }\end{array}$ & Percentage (\%) & $\begin{array}{c}\text { Number of } \\
\text { cases }\end{array}$ & Percentage (\%) & & \\
\hline Control group & 8 & 7.08 & 97 & 85.84 & 8 & 7.08 & & \\
\hline $\begin{array}{l}\text { Experimental } \\
\text { group }\end{array}$ & 10 & 6.84 & 126 & 86.30 & 10 & 6.84 & 0.99 & 0.05 \\
\hline
\end{tabular}

TABLE II. COMPARISON OF INTERNAL CONSISTENCY BETWEEN THE CONTROL GROUP AND THE EXPERIMENTAL GROUP IN 17TH GRADE

\begin{tabular}{|c|c|c|c|c|c|c|c|c|c|c|}
\hline \multirow[t]{3}{*}{ Group } & \multicolumn{8}{|c|}{ Average grade } & \multirow[b]{3}{*}{$\begin{array}{c}\text { Person } \\
\text { Correlatio } \\
\text { n value }\end{array}$} & \multirow[b]{3}{*}{$P$} \\
\hline & \multicolumn{2}{|c|}{ Excellent } & \multicolumn{2}{|c|}{ Good } & \multicolumn{2}{|c|}{ Medium } & \multicolumn{2}{|c|}{ Pass } & & \\
\hline & $\begin{array}{l}\text { Number of } \\
\text { cases }\end{array}$ & $\begin{array}{c}\text { Percentag } \\
\mathrm{e} \\
(\%) \\
\end{array}$ & $\begin{array}{c}\text { Number of } \\
\text { cases }\end{array}$ & $\begin{array}{c}\text { Percentag } \\
\mathrm{e} \\
(\%) \\
\end{array}$ & $\begin{array}{c}\text { Number of } \\
\text { cases }\end{array}$ & $\begin{array}{c}\text { Percentage } \\
\text { (\%) }\end{array}$ & $\begin{array}{l}\text { Number } \\
\text { of cases }\end{array}$ & $\begin{array}{c}\text { Percentage } \\
\text { (\%) }\end{array}$ & & \\
\hline Control group & 3 & 2.73 & 65 & 59.09 & 32 & 29.4 & 10 & & \multirow[b]{2}{*}{1.00} & \multirow[b]{2}{*}{$\stackrel{>}{0.05}$} \\
\hline $\begin{array}{l}\text { Experimental } \\
\text { group }\end{array}$ & 4 & 2.88 & 81 & 58.27 & 41 & 29.50 & 13 & & & \\
\hline
\end{tabular}

\section{B. Method}

The control group and the experimental group have the same course nature, semester, teaching objectives, teaching standards, teaching calendar, teaching progress and teaching content about the course of emergency nursing.

\section{1) Teaching methods of the experimental group}

\section{a) This research conducted two grades of experiments}

Before the start of the course, the research team collected application cases of mind mapping, summarized its characteristics of practical application, and study textbooks deeply to analyze students' learning characteristics and habits. On this basis, the specific plan of applying mind mapping to the course of emergency nursing was improved, and the research group made hand-drawn mind mapping of the chapters taught in each class. Students were divided into groups, 5-6 students a group, and each group had a leader. Before each class, students were trained to draw mind map, and taught about the origin and application purpose of mind mapping, drawing principles, methods and techniques as well as matters needing attention. At the same time, students were allowed to use campus network to study online, and refer to the materials about mind mappings, such as Mind Mapping Method Image Creation (Lu Weici) and Zero Basic Mind Mapping (Sun Yixin). Before the class, the group first drew the mind map with Xmind software, and then revised the mind map drawn by Xmind and drew the mind map for the next class by hand. 
b) The experimental group applied mind mapping teaching method

Before classes, the teaching group would organize and summarize the knowledge points according to the content of the course. First, it used Xmind software to draw the mind map, so as to determine the branching level of the knowledge points, then combined texts with pictures and finally hand-painted the mind map after perfection. Teachers introduced the topic through introducing some cases with the demonstration method and the teaching method, and used the map as study notes, which would be sent to students through the cloud class teaching platform. At the same time, teachers would assign similar cases to student groups to discuss and study. First, student groups could use the Xmind software to modify the map, and then teachers would put forward suggestions on revising the finalized map for each group on the cloud platform, and finally the group could revise and complete the map. The mind maps drawn by each group were posted on the cloud class platform to be evaluated by students, and marks and likes were used as formative evaluation indicators.

\section{2) Teaching method of the control group}

In the preparation stage, teachers prepare lessons in accordance with traditional teaching methods. Teachers release the requirements for pre-class preparation with no specific preparation requirement. The main teaching methods in the classroom teaching stage are teaching and case discussion methods without using mind mapping tool. In the post-class consolidation and expansion stage, teachers assign case analysis questions and the unit theory test to students, and the test scores are used as the formative evaluation indicators for the usual grades.

\section{3) Final exam evaluation for students}

The closed-book exam with "teaching-test separation" method is used to evaluate students at the end of the semester. The final exam will be held for the 16th and 17th students after the end of the 4th semester. Among them, the objective multiple-choice question is 80 points; the case analysis question (20 points) requires students to propose an emergency nursing plan for clinical nursing cases, which is mainly to assess students' clinical emergency nursing ability to treat critically ill patients.

\section{RESUlts}

SPSS20.0 was used to perform two independent sample t-tests on the final exam results of the experimental group and the control group, and the results of the experimental groups of the two grades were significantly higher than the results of the control group ( $\mathrm{P}<0.001, \mathrm{P}<0.001$ ), which was statistically significant. The analysis results are shown in Table III and Table IV below.

TABLE III. T-TEST OF TWO INDEPENDENT SAMPLES FOR THE COMPARISON OF RESULTS BETWEEN CONTROL GROUP AND EXPERIMENTAL GROUP IN 16TH GRADE

\begin{tabular}{|c|c|c|}
\hline Group & Number of cases & $\bar{x} \pm s \quad$ P value \\
\hline Control group & 113 & $85.53 \pm 2.38$ \\
$93.56 \pm 2.86$ & 146 & -30.78 \\
\hline
\end{tabular}

TABLE IV. T-TEST OF TWO INDEPENDENT SAMPLES FOR THE COMPARISON OF RESULTS BETWEEN CONTROL GROUP AND EXPERIMENTAL GROUP IN 17TH GRADE

\begin{tabular}{|c|c|c|c|}
\hline Group & Number of cases & $\bar{x} \pm s$ & $\mathrm{t}$ value value \\
\hline Control group & 110 & $87.16 \pm 2.94$ \\
$93.71 \pm 2.74$ & $<0.001$ \\
\hline
\end{tabular}

\section{DISCUSSION}

The emergency nursing curriculum covers the comprehensive clinical knowledge of internal medicine, surgery and gynecological nursing. At the same time, the rescue process needs to be closely coordinated with medical care. Therefore, it requires students to learn detailed and a large amount of knowledge, which is difficult for students to remember. Using mind mapping for the emergency nursing teaching can organize fragmented pieces of knowledge, give each knowledge point a distinct color, pattern vocabulary and image, and turn a long series of boring information into colorful, easy and highly organized graphics that match the natural way in which the human brain processes things [6]. Mind mapping has two drawing methods: software production and hand-drawing. At present, there is a variety of mind mapping software, such as Mindmapper, Xmind, Free-mind, Inspiration, Infomap, etc., which are easy and fast to operate [7]. This teaching recommends that students use Xmind software to draw the content of the course unit first, and then draw the content of the course unit according to the mind map drawn by the software, so that students can firmly grasp the key content through the thinking and integration of the knowledge points. Teachers give guidance according to the mind map drawn by the students, and then students can revise the map as a class note.

The results show that mind mapping can help students prepare, review and remember, improve self-learning ability, learning interest and learning efficiency, thus improving academic performance (see Table III, Table IV). Preview and review are important parts for students to improve their learning efficiency; therefore, how to control the quality of self-learning before and after class for higher vocational students becomes a key issue. Higher vocational students have less preview time, and the effect of previewing is often uneven. This research allows students to apply the mind mapping in advance, so as to avoid the blindness in the process of preview, improve the preview efficiency, and achieve the teacher's preset goal. In the teaching process, the learning process will be smooth and compact since students have already had cognition. After class, students can continue to modify and improve their mind maps, which will help review. Emergency 
[2] Zhao Guoqing, Lu Zhijian. Analysis of "Concept Mapping" and "Mind Mapping"[J]. China Educational Technology, 2004 (08): 42 - 45.

nursing has the characteristics of complex knowledge and comprehensive content, but as an effective self-learning tool, mind mapping can help students understand and remember the learning content through its intuitive and divergent characteristics [8-9]. Mind mapping enables students to follow the guidelines while learning independently, grasp the difficult and critical points, and improve their learning efficiency [10]. $\mathrm{Li} \mathrm{Li}$ et al [11] applies the mind mapping to the collective preparation of the undergraduate Basic Nursing experimental class. Mind mapping can not only stimulate people's divergent thinking and promote thinking but also take into account the teachers' teaching style and improve the quality of teaching. Ouyang Wenjuan [12] uses mind mapping to build a learning framework system to help students clarify ideas, clarify concepts, and improve learning efficiency. At the same time, teachers can evaluate the learning effect of each student more intuitively according to the mind maps drawn by students. Mind mapping can be used to integrate the interrelation between different disciplines or the repeated contents of the same discipline, present a more intuitive knowledge structure, make knowledge visualization and better display the teaching content.

\section{REFERENCES}

[1] Chen Qi, Liu Rude. Contemporary Educational Psychology[M]. Beijing Normal University Press, 2007.
[3] Liu Wei. Using Mind Mapping to Improve the Teaching of Secondary Vocational Nursing. Chinese General Practice Nursing August, 2015 Vol. 13No. 2.

[4] Hong Ting, Huang Qing, Peng Shengnan et al. Application of Mind Mapping in the Teaching of Internal Medicine. Journal of Jiangxi University of Traditional Chinese Medicine. 2015, 27 (6): 86 - 87,94

[5] Lin Hong, Lu Yiting, Lin Mei. Application of Mind Mapping in Internal Medicine Nursing of Higher Vocational Nursing. Chinese Nursing Education 2015,12(5): 363 - 366

[6] Wu Xiaoyan, Huang Mei, Li Jing, et al. Application of Mind Mapping in the Guidance of Nursing Students in Emergency Department[J]. Journal of Nursing Science, 2012, 27(3): 64 - 65.

[7] Hu Dingwei, Jing Xueming, et al. Application of Mind Mapping in Hospital Admission Guidance for Rheumatology Patients[J]. Journal of Nursing Science, 2011, 26 (9): 73 - 74.

[8] Edwards S, Cooper N. Mind Mapping as a Teaching Resource[J]. Clin Teach, 2010, 7 (4): 236 - 239.

[9] Vanags T, Budimlic M, Herbert E. Showercap Mindmap. Aspatial Activity for Learning Physiology Terminology and Location[J]. Adv Physiol Educ, 2012, 36(2): 125 - 130.

[10] Kong Xia, Li Rong, Zhou Yanfang, et al. Application of Mind Mapping in the Teaching of Pathological Physiology "Hypoxia"[J]. China Higher Medical Education, 2013 (3): 108 - 109.

[11] Li Li, Li Yinfang. Application of Mind Mapping in the Collective Preparation of Experimental Courses in Basic Nursing[J]. Journal of Nursing, 2013, 20(2A): 8 - 10.

[12] Ouyang Wenjuan. Thinking on the Teaching Mode of Psychiatric Nursing[J]. Massage and Rehabilitation Medicine, 2011, 2(6): 208 - 209. 